\title{
Federalismo fiscal no Brasil pós-Constituição Federal de 1988 e seus desdobramentos na primeira metade dos anos de 1990
}

\section{The Fiscal Federalism in Brazil after the Federal Constitution of 1988 and its developments in the first half of the 1990s}

\author{
Fábio Luciano Oliveira Costa ${ }^{1}$
}

\begin{abstract}
Resumo
O objetivo principal deste artigo é investigar a Reforma Tributária promovida pela Constituição Federal de 1988 e suas implicações na primeira metade dos anos de 1990. Apesar da abordagem crítica, que procura analisar os conflitos e as contradições inerentes ao processo social, privilegiou-se a análise governamental, com menor destaque para as lutas dos movimentos sociais. À União coube a maior parte da arrecadação dos tributos, tendo sido privilegiado o aumento das transferências legais entre os entes federados. Os governos municipais, depois de intenso crescimento em seu número, foram os principais beneficiados, elevando suas receitas mais pelas transferências do que pelo aumento do esforço fiscal. Como resultado, entre outros, estruturou-se uma tributação regressiva, em que os trabalhadores acabaram por contribuir mais do que as elites no consumo de mercadorias, em meio a um sistema tido como de baixa qualidade.
\end{abstract}

Palavras-chave: Federalismo Fiscal. Constituição Federal de 1988. Reforma Tributária.

\begin{abstract}
The main objective of this paper is to examine the Tax Reform promoted by the Federal Constitution of 1988 and its implications in the first half of the 1990s. Despite the critical approach, which seeks to analyze the conflicts and contradictions related to the social process, it was focused on the government analysis, with less emphasis for the social movements' struggles. The Union was responsible for most of the taxes collection, and it was favored the rise of legal transfers among the federal entities. The municipal governments, after strong growth, were the primary beneficiaries by increasing their revenues due to the transfers instead of fiscal effort increase. As a result, it was structured a regressive tax where the workers eventually contributed more than the elites in the consumption of goods, in a system considered as of low quality.
\end{abstract}

Key words: Fiscal Federalism. Federal Constitution of 1988. Tax Reform.

\footnotetext{
1 Historiador pela Universidade Federal de Uberlândia. Especialista em Sociologia Política pela Universidade Federal do Paraná. Mestre em Educação pela Universidade Federal do Estado do Rio de Janeiro. Doutorando em Educação pela Universidade de São Paulo. E-mail: fabiolucianocosta@yahoo.com.br.
} 


\section{Introdução}

Este artigo tem como objetivo principal investigar a Reforma Tributária promovida pela Constituição Federal de 1988 (CF/1988) e suas implicações na primeira metade da década de 1990.

Para viabilizar a problemática central, analisa-se a constituição do Sistema Tributário Brasileiro (STB), bem como o papel e a relação dos entes federados no federalismo fiscal, no intuito de melhor compreender as formas de arrecadação e distribuição das riquezas entre os níveis de governo no país.

Apesar da abordagem crítica, que procura analisar os conflitos e as contradições inerentes ao processo social, privilegiou-se a análise governamental, com menor destaque para a luta dos movimentos sociais.

A descentralização fiscal no Brasil foi fruto do processo de redemocratização, com especial atenção para os trabalhos da Assembleia Nacional Constituinte (ANC) em 1987-88, que regularizaram e aprofundaram o processo. Além disso, o mesmo ocorreu em meio à diversidade política, econômica e cultural que perpassava o país, bem como em um período com altas taxas anuais de inflação e sucateamento dos serviços públicos de competência da União.

Para a área fiscal, a ANC de 1987-88 contou com a Comissão do Sistema Tributário, Orçamento e Finanças, que teve como presidente Francisco Dornelles (PFL) e relator José Serra (PMDB).

Boa parte dos constituintes dessa comissão e da Subcomissão de Tributos, Participação e Distribuição de Receitas optaram pelo aumento das alíquotas relativas às transferências legais (com elevação das perdas da União), pela pequena vinculação de gasto de suas receitas e ampliação da autonomia tributária dos governos subnacionais ${ }^{2}$ sobre seus próprios tributos.

Novos centros de poder originaram um emaranhado sistema de dependência política e financeira entre os entes federados pois, a partir de 1988, esses centros puderam acessar ou mesmo ampliar, ainda que de forma desigual, os processos decisórios e colocar em prática determinadas políticas.

\footnotetext{
${ }^{2}$ A União transferiu aos estados a capacidade de taxar sobre combustíveis, comunicação, energia elétrica, minerais e transportes.
}

Cad. de Pesq. Interdisc. em Ci-s. Hum-s., Florianópolis, v.13, n.103, p.92-114, ago/dez 2012 
O próprio sistema tributário criado com a CF/1988 contou com maior participação social, sobretudo de atores que refletiram os conflitos e interesses das arenas políticas.

A ANC de 1987-88 permitiu também a participação direta da população na construção do texto constitucional, por meio das emendas populares, bem como maior autonomia nas concepções dos textos legais, o que não ocorreu nas Constituições anteriores, restritas a especialistas e ao direcionamento de suas formulações.

Para Rezende (1995), a mudança institucional descentralizadora não foi suficiente para por fim ao legado cultural de hábitos e costumes autoritários centralizadores do regime militar para as decisões políticas. Isso porque a autonomia financeira, ao não garantir os tributos necessários para financiar os gastos, elevou as despesas sem o respectivo aumento necessário das receitas para cobri-las, não permitindo a construção de um novo federalismo no Brasil e modificações significativas no STB.

\section{0 sistema tributário brasileiro após a promulgação da CF/1988}

Os tributos no país são classificados, de acordo com o art. 145 da CF/1988, em impostos, taxas e contribuições de melhoria. Os empréstimos compulsórios e as contribuições especiais ou parafiscais (arts. 148 e 149) apareceram no STB com as mesmas características dos tributos e como eles são tratados.

Em comparação aos demais tributos, os impostos não necessariamente apresentam correlação entre seu fato gerador a uma ação do Estado, associada ao contribuinte, enquanto as taxas objetivam compensar o uso efetivo ou potencial de serviços públicos oferecidos ao contribuinte, boa parte delas cobradas pelo governo federal. Já as contribuições de melhoria têm a função de fornecer os recursos para a realização de obras públicas provenientes de valorização imobiliária.

Segundo o art. 148 da CF/1988, os empréstimos compulsórios cumprem a função de atender às despesas extraordinárias decorrentes de calamidade pública, de guerra externa ou sua iminência, ou são usados para cobrir despesas com investimento público de caráter urgente e relevante interesse social, além de serem restituíveis. 
As contribuições especiais, pelo art. 149, podem ser sociais, de intervenção no domínio econômico ou de interesses de categorias profissionais ou econômicas.

Os tributos podem ser: 1) vinculados (taxas, contribuições de melhoria, empréstimos compulsórios e contribuições especiais ou parafiscais), que exigem alguma forma de contraprestação do Estado voltada para o contribuinte direta ou indiretamente; e 2) não-vinculados (impostos), que não exigem contraprestação do Estado de obras ou serviços para o contribuinte.

A cobrança do tributo pode ser direta, quando em uma só pessoa é reunida as condições de contribuinte, que tem a função de cumprir com todas as obrigações tributárias previstas na legislação; ou indireta, quando se estabelece uma relação jurídica e tributária entre $\circ$ Estado e contribuinte, $\circ$ qual paga $\circ$ tributo correspondente e recebe determinado ressarcimento pelas instituições estatais, com a inclusão do tributo no preço do serviço.

Assim, no caso da segunda, o valor do tributo é repassado para o valor final do bem e serviço, pago pelos consumidores sem distinção de poder aquisitivo, ou seja, indivíduos pobres pagam relativamente mais do que os ricos. O Quadro 1 mostra os principais tributos diretos e indiretos do STB.

Quadro 1: Principais tributos diretos e indiretos do STB

\begin{tabular}{|c|c|c|c|}
\hline \multicolumn{4}{|c|}{ TRIBUTOS } \\
\hline \multicolumn{2}{|l|}{ Diretos } & \multicolumn{2}{|c|}{ Indiretos } \\
\hline $\begin{array}{c}\text { Contribuição para a previdência } \\
\text { social }\end{array}$ & $\mathrm{IPVA}^{1}$ & $\mathrm{ICMS}^{2}$ & COFINS $^{2}$ \\
\hline Imposto de Renda (IR) & IPTU' $^{1}$ & IPI e ISS ${ }^{2}$ & $\begin{array}{c}\text { Contribuição para o PIS- } \\
\text { PASEP² }\end{array}$ \\
\hline $\begin{array}{l}\text { Contribuição para o FGTS'1 } \\
\text { Imposto Territorial Rural (ITR) }\end{array}$ & & $\begin{array}{l}\text { Imposto sobre } \\
\text { Importação (II) }\end{array}$ & $\begin{array}{l}\text { Contribuição Social sobre o } \\
\text { Lucro Líquido (CSLL) }\end{array}$ \\
\hline $\begin{array}{l}\text { Contribuição para o salário- } \\
\text { educação }\end{array}$ & Outros & $\begin{array}{l}\text { Imposto sobre Operações } \\
\text { Financeiras (IOF) }\end{array}$ & Outros \\
\hline
\end{tabular}

(1) Fundo de Garantia do Tempo de Serviço (FGTS); Imposto sobre a Propriedade de Veículos Automotores (IPVA); Imposto Predial e Territorial Urbano (IPTU); (2) Imposto sobre Circulação de Mercadorias e Serviços (ICMS); Imposto sobre Produtos Industrializados (IPI); Imposto sobre Serviços de Qualquer Natureza (ISS); Contribuição para o Financiamento da Seguridade Social (COFINS); Programa de Integração Social (PIS); Programa de Formação do Patrimônio do Servidor Público (PASEP).

Fonte: Varsano et al. (1998). Elaboração do autor. 
Os tributos podem ter incidência cumulativa (efeito em cascata), quando incidem de forma recorrente em todas as etapas intermediárias da produção, elevando o preço das mercadorias ou dos serviços em cada uma dessas fases, como no caso do PIS/PASEP, da COFINS, CSLL e da extinta Contribuição Provisória sobre Movimentação Financeira ${ }^{3}$ (CPMF); ou podem ter incidência nãocumulativa, ainda que com algum tipo de cumulatividade, não incidindo sobre o mesmo tributo pago na etapa anterior da produção, caso do ICMS e do IPI.

Para a União, que arrecada a maior parcela dos tributos, os impostos que lhe são exclusivos correspondem ao IOF (com exceção do IOF-ouro), Imposto de Exportação (IE), Imposto de Importação (II) e Imposto sobre Grandes Fortunas (IGF). Cabe ainda ao governo federal o percentual de impostos restantes resultantes da partilha com os estados e municípios, no caso, o IR ( $52 \%$ do total), IPI ( $42 \%$ do total) e ITR (50\% do total).

Também há os recursos arrecadados com a seguridade social que não entram nas cotas das transferências legais vinculadas, como a cobrança de empréstimos compulsórios e contribuições sociais sobre o lucro líquido, mão de obra (FGTS, previdência social, salário-educação e de servidores), receita e faturamento geral (COFINS e PIS/PASEP), além de outros tributos.

Aos estados (Distrito Federal), a apropriação exclusiva diz respeito à previdência estadual, ao Imposto de Transmissão Causa Mortis e Doação (ITCMD), taxas estaduais e outros tributos, sendo que, após a repartição com os municípios, cabem aos estados $75 \%$ do ICMS e $50 \%$ do IPVA.

Para os municípios, a apropriação exclusiva compete ao ISS, IPTU e ITBI (Imposto de Transmissão de Bens Imóveis Inter-Vivos), taxas municipais, previdência municipal e outros tributos.

À União não foi mais possível permitir isenções de impostos estaduais e municipais, além de retiradas para esses governos as condições ou restrições dos repasses e/ou gastos dos recursos recebidos. A capacidade de tributar, definida para os entes federados, não os autoriza a criar novos impostos sem a aprovação de uma EC, a não ser por duas exceções: uma, em caso de guerra iminente; outra,

\footnotetext{
${ }^{3}$ O Imposto Provisório sobre Movimentação Financeira (IPMF) - tributo cumulativo criado pela LC $\mathrm{n}^{\circ}$ $77 / 1993$-, vigorou de $1^{\circ}$ de janeiro de 1994 , até 31 de julho de 1994, com alíquota de 0,25\% que incidia sobre os débitos lançados nas contas pelas instituições financeiras. Em seguida, originou a CPMF, agora como contribuição social, por meio da EC n 12/1996.
} 
para financiar o sistema de seguridade social, embora exija a sanção do Congresso Nacional, mas sem a necessidade de supermaioria.

O Quadro 2 corresponde às transferências legais de impostos da União para os estados e municípios, além daquelas efetuadas dos estados para seus municípios, após a promulgação da CF/1988.

Quadro 2: Transferência legal de impostos entre os entes federados, após a promulgação da CF/1988

\begin{tabular}{|c|c|c|}
\hline Transferência & Estados e Distrito Federal' & Municípios \\
\hline União & $\begin{array}{l}\text { *21,5\% da arrecadação do IR (excluída a parcela da arrecadação } \\
\text { de estados, Distrito Federal e municípios) e IPI para o Fundo de } \\
\text { Participação dos Estados (FPE) (art. 159, I, a); } \\
\text { * } 10 \% \text { da arrecadação do IPI-exportação, proporcionalmente ao } \\
\text { valor das exportações de bens industrializados (art. 159, II); } \\
\text { * } 29 \% \text { da Contribuição de Intervenção no Domínio Econômico } \\
\text { (CIDE) relativa às atividades de importação ou comercialização de } \\
\text { petróleo e seus derivados, gás natural e seus derivados e álcool } \\
\text { combustível (art. 159, III); } \\
\text { * } 30 \% \text { do IOF-ouro, quando definido em lei como ativo financeiro } \\
\text { ou ativo cambial (art. 153, § 5 , I); } \\
\text { * } 20 \% \text { da arrecadação dos impostos residuais (art. 157, II). }\end{array}$ & $\begin{array}{l}\text { * } 22,5 \% \text { da arrecadação do IR (excluída a parcela } \\
\text { de arrecadação de estados, Distrito Federal e } \\
\text { municípios) e IPI para o Fundo de Participação } \\
\text { dos Municípios (FPM) (art. 159, I, b); } \\
\text { * } 70 \% \text { do IOF - ouro quando definido em lei como } \\
\text { ativo financeiro ou ativo cambial para o município } \\
\text { de sua origem - IOF-ouro (art. 153, § 50, II); } \\
\text { * } 50 \% \text { do produto da arrecadação do ITR relativos } \\
\text { aos imóveis nele situados (art. 158, II). }\end{array}$ \\
\hline Estados & & 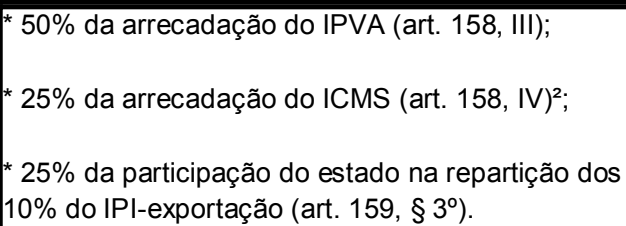 \\
\hline
\end{tabular}

(1) Torres et al. (2003, p. 379) coloca que a totalidade do IR dos funcionários dos estados, Distrito federal e municípios corresponde a partilha de tributos, ou seja, "receita tributária direta do governo subnacional" e não à PA, incorrendo em erros quando classificada como receita de transferência.

(2) Conforme o art. 158, parágrafo único, incisos I e II, da CF/1988, as parcelas da repartição serão feitas por meio de $75 \%$, no mínimo, na proporção do valor adicionado nas operações relativas à circulação de mercadorias e nas prestações de serviços, realizadas em seus territórios; até $25 \%$, de acordo com disposição em lei estadual.

Fonte: Brasil (2008). Elaboração do autor.

O ICMS, principal tributo na arrecadação do país, teve suas bases de incidência aumentadas. Esse imposto, que possui legislação diferenciada para cada um dos estados e o Distrito Federal, como a fixação de alíquotas, coloca o Brasil mais uma vez em posição singular, quando comparado com outras federações, no que diz respeito à forma como legislam o tributo de maior participação na arrecadação sobre a carga tributária (sob a responsabilidade do governo federal).

A cobrança desse imposto ocorre na origem da produção do bem e serviço e não no seu destino, apresentando-se como ponto de extrema importância no pacto 
federativo e para a Reforma Tributária. Com isso, os governos estaduais mais ricos não querem perder a capacidade de tributação sobre o ICMS, pois comprometeriam suas finanças, já que ocorre o direcionamento de verbas desses locais para os estados mais pobres, por meio de outros mecanismos redistributivos. Dessa forma, impede-se a redução das acentuadas desigualdades interestaduais no país.

Pelo fato de poderem oferecer incentivos fiscais similares sobre o imposto, na década de 1990, cresceu a guerra fiscal do ICMS, em que o estado que não concedesse incentivos teria limitada a possibilidade de receber empreendimentos, principalmente aqueles associados aos grandes capitais. Outros fatores de natureza socioeconômica (como mão de obra barata, menor atuação dos sindicatos, entre outros) passaram a ser determinantes nesse processo, às vezes com peso maior do que a própria concessão de benefícios fiscais, compensados com a redução da receita pública.

Ao substituir o Imposto sobre Circulação de Mercadorias (ICM), o ICMS permitiu aos estados autonomia para fixar suas alíquotas. De acordo com Varsano (1996), as restrições que ainda permaneceram e muitos dos problemas no sistema tributário poderiam ter sido superados caso tivessem sido derrubadas as barreiras quanto às novas propostas de modificações e mesmo diminuição das receitas, ainda que compensadas por alterações propostas pelos governos subnacionais e por grupos de constituintes com fortes interesses regionais e/ou locais.

Com a preferência pela ampliação das transferências legais, junto com o deslocamento de cinco impostos federais (combustíveis e lubrificantes, eletricidade, produtos minerais, serviços de comunicações e transportes), incorporados à base do $\mathrm{ICMS}^{4}$, além da oscilação nos indicadores econômicos ${ }^{5}$ e da má administração fazendária, reduziram-se os recursos disponíveis da União ${ }^{6}$.

A tributação brasileira é tida como regressiva, pois para a tributação indireta, as alíquotas são inseridas de forma a não discriminar sobre a essencialidade dos produtos, principalmente sobre bens e serviços, o que faz com que os trabalhadores contribuam mais do que as elites no consumo de mercadorias.

\footnotetext{
${ }^{4}$ De 1988 a 1994, a carga do ICMS passou de 5,3\% para 7,3\% do Produto Interno Bruto (PIB) (AMORIM, 2001).

${ }^{5}$ As taxas de crescimento anual, de 1986 a 1990, foram de 7,8\%,7,5\%,3,5\%, $-0,1 \%$ e 3,5\% (CARCANHOLO, 2002).

${ }^{6}$ A redução dos recursos da União não foi acompanhada pela diminuição de suas atribuições, compactuando, em muitos casos, com o processo de desconcentração e não propriamente de descentralização.
}

Cad. de Pesq. Interdisc. em Ci-s. Hum-s., Florianópolis, v.13, n.103, p.92-114, ago/dez 2012 
Além disso, a baixa incidência dos tributos sobre a renda, especialmente sobre as pessoas físicas, bem como, entre outros, a criação de tributos cumulativos da seguridade social, ou a ampliação das alíquotas daqueles já existentes, centralizados pela União, após a promulgação da CF/1988, dificultaram o estabelecimento de melhorias qualitativas no STB.

Estudos apontados por Dain (2005), para a década de 1990, indicaram que os indivíduos que ganhavam até dois salários mínimos pagavam aproximadamente $26 \%$ de impostos indiretos, enquanto que para os que ganhavam mais de 30 salários mínimos, os índices se aproximaram de 8\%, diferença essa que não foi amenizada com a tributação sobre a renda, que incide principalmente nas pessoas jurídicas, propícia para incentivar a formação de grandes oligopólios. Ainda acrescenta-se a esses fatores, conforme a autora, a contribuição desproporcional relacionada ao poder aquisitivo das grandes fortunas, sobrecarregando as camadas com rendas intermediárias. Ao somar os impostos diretos e indiretos, os valores corresponderam a $27 \%$ para os primeiros e $18 \%$ para os segundos.

Para compensar os efeitos perversos do STB, a CF/1988 ampliou as transferências legais no país, por exemplo, com o Fundo de Compensação pela Exportação de Produtos Industrializados (FPEX), criado para compensar a desoneração fiscal do ICMS sobre essas exportações, por meio do qual são redistribuídos $10 \%$ da arrecadação do IPI, de acordo com o volume de exportações de cada ente federado.

Posteriormente, com a Lei Kandir, em 1996, as desonerações se estenderiam aos produtos semielaborados e primários e implantaria o Seguro-Receita, que também retiraria a "tributação sobre bens destinados ao ativo fixo e consumo próprio das empresas" (TORRES et al., 2003, p. 346).

As transferências legais redistributivas, como o $\mathrm{FPE}$ e o $\mathrm{FPM}^{7}$, tiveram elevadas suas alíquotas para 21,5\% e 22,5\% com a CF/1988, alcançando esses índices a partir de 1993. A redistribuição do FPE passou a direcionar $85 \%$ do seu montante total para as regiões Norte, Nordeste e Centro-Oeste e 15\% para as regiões Sudeste e Sul, distribuídos de acordo com o número populacional e inverso da renda per capita (regiões mais pobres recebem mais). A porcentagem fixa dos recursos recebidos para as cinco regiões brasileiras com os repasses do FPE

\footnotetext{
${ }^{7}$ Com exceção das vinculações constitucionais para a educação e saúde, os recursos dos Fundos podem ser gastos com bastante autonomia pelos governos subnacionais.
}

Cad. de Pesq. Interdisc. em Ci-s. Hum-s., Florianópolis, v.13, n.103, p.92-114, ago/dez 2012 
correspondeu a $52,46 \%$ para o Nordeste, $25,37 \%$ para o Norte, $8,48 \%$ para o Sudeste, 7,17\% para o Centro-Oeste e 6,52\% para o Sul (LC n ${ }^{\circ} 62 / 1989$ ).

Ao fixar esses critérios, a lei estabeleceu uma política redistributiva, mas ao congelar os fatores que definiram os coeficientes para cada estado, há mais de duas décadas, substituindo-os por uma tabela que determina a participação estadual no FPE e dos municípios de cada estado no FPM, para Prado (2003), citado por Cruz (2009, p. 126), "terminou por enrijecer o sistema, perdendo a capacidade de adaptação dinâmica de seus critérios de distribuição às mudanças demográficas e econômicas".

A atuação do FPE é bastante diferenciada no país. No plano vertical, o Fundo reduz as desigualdades entre as regiões, mas no horizontal, elevam-se as diferenças, sobretudo na região Norte, que privilegia estados menos populosos, em detrimento dos de maior população, onde estados pobres recebem transferências com desigualdades proporcionais. Nas regiões Centro-Oeste e Sul, o Fundo diminui as desigualdades entre os estados; na Sudeste, verifica-se certa neutralidade (ibidem).

No plano intra-regional, como os estados das regiões Centro-Oeste, Nordeste e Norte receberam a maior parte dos recursos do FPE, criaram-se as bases para a elevação das desigualdades econômicas entre as regiões brasileiras.

Já para o FPM, os critérios de repasse corresponderam a 10\% para as capitais, $86,4 \%$ para os municípios não-capitais e $3,6 \%$ para os municípios não-capitais com mais de 156.216 habitantes (que também receberam a cota do Fundo referente ao critério de distribuição populacional). Isso ainda segundo o Decreto-Lei $n^{\circ}$ $1.881 / 1981$, mediante as diferenças de peso para a distribuição por estados e regiões, que em 1988 foram estabelecidos em $35,22 \%$ para o Nordeste, $31,22 \%$ para o Sudeste, $17,61 \%$ para o Sul, $8,52 \%$ para o Norte e $7,43 \%$ para o CentroOeste.

A lógica desse Fundo esteve sempre ligada à perspectiva de compensar as limitações impostas pela capacidade de tributação dos pequenos municípios. Os que possuem menos de 5.000 habitantes têm elevados, não raro, depois das transferências legais, sua renda per capita muito acima dos de médio ou grande 
porte $^{8}$, impedindo a redução das desigualdades horizontais e maior equilíbrio nas desigualdades econômicas no país. Ainda, privilegiou também as capitais, com a participação na arrecadação em duas das cotas de repasses dos recursos no Fundo.

Outros critérios, como as novas informações populacionais, de infraestrutura urbana e crescimento das metrópoles nas duas últimas décadas, teriam que ser levados em conta para remodelar a redistribuição dos recursos dos Fundos, no sentido de melhorar sua equalização. Assim, ao citar Dain (1995), Cruz (2009, p. 129) apresenta a seguinte perspectiva:

\begin{abstract}
Para autores como Dain, hoje já não se justificam mais tais critérios, em especial aqueles que determinam que $85 \%$ do FPE sejam dirigidos para as regiões Norte, Nordeste e Centro-Oeste e que os municípios pequenos sejam mais contemplados com os recursos do FPM. Essa análise está pautada na percepção das mudanças na dinâmica de produção e de ocupação espacial do país, resultando a concentração de problemas sociais nas cidades de médio porte (mais punidas pelo sistema de repasse do FPM) e nas regiões metropolitanas, que sofrem todas as formas de carência de infraestrutura urbana, instituindo os chamados bolsões de miséria.
\end{abstract}

De acordo com a CF/1988 (art. 159, inciso I, c), 3\% da arrecadação do IR e do IPI passaram a compor os programas de financiamento do setor produtivo das regiões Centro-Oeste, Nordeste e Norte, depois de extinto o Fundo Especial.

Com a Lei $n^{\circ} 7.827 / 1989$, instituíram-se os Fundos de Financiamento do Centro-Oeste, Nordeste e Norte, cujos percentuais de distribuição corresponderam a 0,6\% para o primeiro, administrados pelo Banco do Brasil, 1,8\% para o segundo, administrados pelo Banco do Nordeste e $0,6 \%$ para o terceiro, administrados pelo Banco da Amazônia.

A definição sobre a divisão dos recursos entre os entes federados foi claramente especificada na CF/1988.

Segundo a Tabela 1, na década de 1980, a Participação na Arrecadação (PA) da União teve diminuição de 7,2 pontos percentuais (p.p.), enquanto para os estados, o aumento foi de 8,3 p.p., constituindo-se esses governos nos principais beneficiários da descentralização-desconcentração, possibilitada pela redemocratização, no que se refere à arrecadação dos recursos tributários.

\footnotetext{
${ }^{8}$ Apesar das diferenças, em termos absolutos, os recursos foram insuficientes para resolver os problemas financeiros desses pequenos municípios.
}

Cad. de Pesq. Interdisc. em Ci-s. Hum-s., Florianópolis, v.13, n.103, p.92-114, ago/dez 2012 
Tabela 1: Participação na Arrecadação (PA), em \% do total, dos entes federados sobre a carga tributária (\% do PIB), de 1980 a 1989

\begin{tabular}{ccccccccccccc}
\hline PA & $\mathbf{1 9 8 0}$ & $\mathbf{1 9 8 1}$ & $\mathbf{1 9 8 2}$ & $\mathbf{1 9 8 3}$ & $\mathbf{1 9 8 4}$ & $\mathbf{1 9 8 5}$ & $\mathbf{1 9 8 6}$ & $\mathbf{1 9 8 7}$ & $\mathbf{1 9 8 8}$ & $\mathbf{1 9 8 9}$ \\
\hline União & 74,7 & 75,4 & 75,9 & 76,6 & 73,6 & 72,7 & 70,5 & 72,3 & 71,7 & 67,5 \\
Estados & 21,6 & 21,3 & 21,4 & 20,6 & 23,7 & 24,9 & 27,0 & 25,2 & 25,6 & 29,9 \\
Municípios & 3,7 & 3,3 & 2,7 & 2,8 & 2,7 & 2,4 & 2,5 & 2,5 & 2,7 & 2,7 \\
Carga tributária & 24,5 & 25,3 & 26,3 & 27,0 & 24,3 & 24,1 & 26,2 & 23,8 & 22,4 & 24,1 \\
\hline
\end{tabular}

Fonte: Varsano et al. (1998).

Com exceção de 1987 (23,8\%) e 1988 (22,4\%), durante toda a década a carga tributária oscilou entre $24 \%$ e $27 \%$ do $\mathrm{PIB}^{9}$.

Fatores como, entre outros, o desempenho do Estado na economia, acesso e controle à base imponível, arrecadação da previdência social pública, tamanho médio das empresas que determinam a participação na renda do trabalho, distribuição funcional da renda, participação da população economicamente ativa no trabalho, saldo na balança comercial e inflação modificam a variação da carga tributária. Principalmente com a elevação das transferências legais, a ampliação da cota dos governos subnacionais (especialmente dos municípios) na repartição do bolo tributário pôde ser expressa, por exemplo, com a participação na Receita Disponível (RD) da carga tributária, de 1980 a 1989.

De acordo com a Tabela 2, a União teve redução de 7,1 p.p. na $\mathrm{RD}$, em contraposição, a elevação para os estados atingiram 1,7 p.p. e para os municípios 5,3 p.p.

Tabela 2: Receita Disponível (RD), em \% do total, dos entes federados sobre a carga tributária (\% do PIB), de 1980 a 1989

\begin{tabular}{ccccccccccccc}
\hline RD & $\mathbf{1 9 8 0}$ & $\mathbf{1 9 8 1}$ & $\mathbf{1 9 8 2}$ & $\mathbf{1 9 8 3}$ & $\mathbf{1 9 8 4}$ & $\mathbf{1 9 8 5}$ & $\mathbf{1 9 8 6}$ & $\mathbf{1 9 8 7}$ & $\mathbf{1 9 8 8}$ & $\mathbf{1 9 8 9}$ \\
\hline União & 68,2 & 68,4 & 69,0 & 69,8 & 65,8 & 62,7 & 60,9 & 64,1 & 60,1 & 61,1 \\
Estados & 23,3 & 22,3 & 22,1 & 21,3 & 24,1 & 26,2 & 27,0 & 23,3 & 26,6 & 25,0 \\
Municípios & 8,6 & 9,3 & 8,9 & 8,9 & 10,1 & 11,1 & 12,1 & 12,6 & 13,3 & 13,9 \\
Carga tributária & 24,5 & 25,3 & 26,3 & 27,0 & 24,3 & 24,1 & 26,2 & 23,8 & 22,4 & 24,1 \\
\hline
\end{tabular}

Fonte: Varsano et al. (1998).

\footnotetext{
${ }^{9}$ Diversas instituições fornecem dados referentes à carga tributária no país, como a Secretaria da Receita Federal (SRF), o Instituto Brasileiro de Geografia e Estatística (IBGE), a Secretaria para Assuntos Fiscais do Banco Nacional de Desenvolvimento Econômico e Social (BNDES) e o Tribunal de Contas da União (TCU). Pela falta de uma metodologia fixa no cálculo, os dados podem variar conforme a instituição.
}

Cad. de Pesq. Interdisc. em Ci-s. Hum-s., Florianópolis, v.13, n.103, p.92-114, ago/dez 2012 
Os estados conseguiram aumentar sua arrecadação fiscal própria, o que também teve reflexos na elevação das despesas disponíveis, mas nos municípios, o importante crescimento ocorreu pelo aumento das transferências legais e negociadas.

No ano de 1990, segundo dados fornecidos pela SRF, a contribuição de Tributos sobre Bens e Serviços, segundo o Quadro 3, que inclui o ICMS, IPI, PIS, PASEP e a COFINS, entre outros, respondeu por $49,06 \%$ da arrecadação total.

Quadro 3: Principais bases de incidência dos tributos sobre o STB

\begin{tabular}{|c|c|c|c|c|c|}
\hline $\begin{array}{c}\text { Tributos } \\
\text { sobre Bens e } \\
\text { Serviços } \\
\text { (TBS) }\end{array}$ & $\begin{array}{c}\text { Tributos sobre a } \\
\text { Mão de Obra (TMO) }\end{array}$ & $\begin{array}{l}\text { Tributos } \\
\text { sobre } \\
\text { a Renda } \\
\text { (TR) }\end{array}$ & $\begin{array}{l}\text { Tributos } \\
\text { sobre o } \\
\text { Comércio } \\
\text { Exterior } \\
\text { (TCE) }\end{array}$ & $\begin{array}{c}\text { Tributos } \\
\text { sobre o } \\
\text { Patrimônio } \\
\text { (TP) }\end{array}$ & \multirow{5}{*}{ Outros } \\
\hline ICMS PIS & $\begin{array}{l}\text { Contribuição para a } \\
\text { Previdência Social }\end{array}$ & IR & \multirow{3}{*}{ II } & IPTU & \\
\hline PASEP & Contribuição para o FGTS & & & IPVA & \\
\hline ISS & $\begin{array}{c}\text { Contribuição para o } \\
\text { salário-educação }\end{array}$ & CSLL & & ITR & \\
\hline OFINS Outros & $\begin{array}{l}\text { Contribuição de } \\
\text { servidores }\end{array}$ & & & & \\
\hline
\end{tabular}

Fonte: Varsano et al. (1998).

Em seguida, as principais contribuições corresponderam aos Tributos sobre a Mão de Obra (25,28\%), que envolve a contribuição para a previdência, o FGTS, salário-educação e os servidores; Tributos sobre a Renda (19,72\%), como o IR e a CSLL; Tributo sobre Comércio Exterior (1,35\%), a exemplo do II; Tributos sobre o Patrimônio $(0,96 \%)$, como o IPTU, IPVA e ITR; além de outros Tributos $(3,63 \%)$, diretos e indiretos.

A Tabela 3 mostra a contribuição individual de alguns desses tributos para o ano de 1990 , onde só o ICMS acumulou mais de $25 \%$ de toda a arrecadação (constituindo-se na principal fonte para o aumento da participação fiscal dos estados), seguido pela contribuição para a previdência e o IR. 
Tabela 3: Participação na Arrecadação (PA), em \% do total, dos principais tributos sobre a carga tributária, em 1990

\begin{tabular}{|c|c|c|c|c|c|c|c|c|c|}
\hline Principais & ICMS & IR & Prev. & COFINS & FGTS & IPI & PIS/PASEP & CSLL & Outros \\
\hline
\end{tabular}

Fonte: SRF, 1996. Elaboração do autor.

A elevação dos recursos municipais levou ao crescimento do número de municípios pequenos. Principalmente nas regiões mais desenvolvidas, os governos locais adotaram medidas, por exemplo, para aumentar a arrecadação própria. $\mathrm{O}$ crescimento ocorreu por meio da capacidade de taxar sobre a propriedade urbana, os serviços e a transferência de propriedade, ainda que restrita pela determinação das alíquotas dos tributos estabelecidas em Lei Complementar.

\section{0 papel dos entes federados no federalismo fiscal brasileiro}

Também foi adotado o incentivo ao crescimento econômico para que os governos municipais viessem a obter maiores repasses nas cotas estaduais do ICMS e oferecer concessões fiscais a grandes empresas, desencadeando um processo de guerra fiscal que, por vezes, beneficiou mais as empresas do que os governos subnacionais que as concederam, pela falta de uma política nacional de industrialização.

Uma das consequências desse processo de crescimento, em relação ao gasto com o legislativo per capita médio anual no país, foi que os municípios com até 5.000 habitantes gastaram, em média, $32,05 \%$ a mais do que aqueles com mais de 1.000.000 de habitantes para essa despesa, que envolveu prefeitos, vice-prefeitos, vereadores, assessores e burocratas em geral, em detrimento das políticas sociais e dos investimentos nos diversos níveis de governo (GOMES; MACDOWELL, 2000).

A problemática também esteve relacionada com a saída de recursos de locais que ainda apresentavam elevada carga de problemas sociais, como as grandes regiões metropolitanas, as quais exportavam (e ainda exportam) recursos para outros municípios e outras regiões, com maior sobrecarga em períodos de crise econômica.

Ora, se locais que precisam de novos investimentos acabam por ter a fuga de recursos, a capacidade dos governos subnacionais em fornecer serviços essenciais 
diminui, a exemplo da educação, saúde e infraestrutura, provocando o desestímulo à atividade econômica. Ainda, as transferências, legais e negociadas, também não conseguiram resolver os agravantes sociais dos pequenos municípios.

No entanto, Souza (2001) apresentou argumento parcialmente contraditório a essa tendência, pois 11 capitais, de 1989 a 1994, teriam aumentado suas receitas próprias em mais de $10 \%$, consequentemente reduzindo a dependência com relação às transferências federais e estaduais e aumentando os investimentos em programas considerados prioritários pelas elites políticas locais.

Tais municípios, menos da metade das capitais no país, ainda refletiram as diferenças locais e regionais subsidiadas nesse período pelo processo de descentralização, que não levou necessariamente à democratização do poder local, graças também ao ainda incipiente controle social nas ações do poder público, principalmente em municípios pequenos e pobres, mesmo com as melhorias desencadeadas na gestão de suas políticas, muitas vezes com sérias deficiências na qualidade da burocracia local. Quanto menores os vínculos entre transferência e gastos, maiores as probabilidades de "descontrole" e "desperdício" (REZENDE, 1995, p. 13).

O equilíbrio entre receitas próprias e transferências, somado à reestruturação dos mecanismos tributários, financeiros e administrativos que possam permitir maior autonomia no desenvolvimento dos governos subnacionais (sobretudo para os mais carentes) e ao regime de colaboração entre os entes federados, bem como à correção dos desequilíbrios nas atividades econômicas que geram emprego e renda, permitiriam elevar a eficiência do federalismo fiscal no Brasil.

Tudo isso se relaciona com o controle social, que poderá ter maior atuação mediante a conscientização da população sobre o funcionamento das regras fiscais no país, o que permitirá a transformação do sistema com justiça social, ou seja, a responsabilidade do cidadão tende a influenciar na eficiência governamental. No entanto, as competências compartilhadas estabelecidas na CF/1988 não permitiram que os entes federados definissem com clareza os meios para que a população pudesse cobrar maior responsabilidade e melhor governabilidade desses níveis de governo.

Com o aumento das receitas para os estados e municípios, elevaram-se também as despesas, principalmente aquelas relacionadas com os gastos do funcionalismo ativo, as compras de bens e serviços e os investimentos fixos. 
Ao governo federal ainda coube a preponderância sobre as despesas com juros e encargos da dívida pública ${ }^{10}$, o pagamento dos segurados da previdência (social/básica ou dos servidores federais inativos), a cobertura dos saques do FGTS e do seguro desemprego.

Os gastos de consumo para os estados e municípios aumentaram de $6,3 \%$ do PIB, em 1970, para 9,6\%, em 1991; com o funcionalismo, de $4,7 \%$, para $6,5 \%$ (principalmente com salários em áreas como saúde e educação) (ibidem).

Para recompor parte das perdas com a descentralização fiscal determinada pela CF/1988, ainda na primeira metade dos anos 1990, a União adotou como estratégia a ampliação das alíquotas de tributos já existentes (a exemplo da CSLL, COFINS e do IOF), ou a criação de outros, como o IPMF, além de manter sua exclusividade para poder criar contribuições sociais e tributos sobre o campo residual.

As contribuições sociais que, segundo Pinto (2000), em âmbito federal somavam mais de cinquenta em meados dos anos de 1990 e deveriam financiar parte das políticas sociais, não entraram na cota dos repasses de recursos constitucionalmente vinculados e direcionados para os estados e municípios, como no caso da educação e saúde, mas em parte, foram (e são) negociadas entre os entes federados.

No período de 1988 a 1990, a pequena participação das transferências negociadas em relação ao PIB diminuiu de 0,69\% para 0,28\% (SERRA; AFONSO, 1991 apud ABRUCIO; COUTO, 1996). Mesmo assim, os estados com maior volume dessas transferências geralmente foram aqueles que integraram a coalizão de apoio ao governo federal, já estados governados pela oposição tenderam a receber menos recursos.

A Tabela 4 mostra a Participação na Arrecadação (PA) dos entes federados sobre a carga tributária, de 1990 a 1994. Nesse período, mas em menor proporção do que ocorreu durante os anos de 1980, evidenciou-se a perda de recursos para os estados em 2,2 p.p., depois dos ganhos obtidos na década anterior, e o aumento para a União e os municípios, respectivamente em 0,9 p.p. e 1,3 p.p.

\footnotetext{
${ }^{10} \mathrm{Em} 1989$, a dívida externa chegou a $\mathrm{R} \$ 115,5$ bilhões e o total de juros da dívida pagos em toda a década a US $\$ 97,3$ bilhões (CARCANHOLO, 2002).
}

Cad. de Pesq. Interdisc. em Ci-s. Hum-s., Florianópolis, v.13, n.103, p.92-114, ago/dez 2012 
Tabela 4: Participação na Arrecadação, em \% do total, dos entes federados sobre a carga tributária (\% do PIB), de 1990 a 1994

\begin{tabular}{ccc|c|c|c|}
\hline PA & $\mathbf{1 9 9 0}$ & $\mathbf{1 9 9 1}$ & $\mathbf{1 9 9 2}$ & $\mathbf{1 9 9 3}$ & $\mathbf{1 9 9 4}$ \\
\hline União & 67,0 & 63,4 & 66,2 & 68,6 & 67,9 \\
Estados & 29,6 & 31,1 & 29,3 & 26,6 & 27,4 \\
Municípios & 3,4 & 5,5 & 4,5 & 4,8 & 4,7 \\
Carga tributária & 30,0 & 26,0 & 25,9 & 26,4 & 28,6 \\
\hline
\end{tabular}

Fonte: Almeida (2005). Elaboração do autor.

Conforme a Tabela 5 mostra, a União, de 1990 a 1994, teve aumento de 2,8 p.p., principalmente pela elevação dos recursos da seguridade social, os quais não entraram na repartição constitucional das transferências legais.

Tabela 5: Receita Disponível (RD), em \% do total, dos entes federados sobre a carga tributária (\% do PIB), de 1990 a 1994

\begin{tabular}{ccc|c|c|c|}
\hline RD & $\mathbf{1 9 9 0}$ & $\mathbf{1 9 9 1}$ & $\mathbf{1 9 9 2}$ & $\mathbf{1 9 9 3}$ & $\mathbf{1 9 9 4}$ \\
\hline União & 56,6 & 53,4 & 57,0 & 57,8 & 59,4 \\
Estados & 28,5 & 29,5 & 28,1 & 26,4 & 25,4 \\
Municípios & 14,9 & 17,1 & 14,9 & 15,8 & 15,2 \\
Carga tributária & 30,0 & 26,0 & 25,9 & 26,4 & 28,6 \\
\hline
\end{tabular}

Fonte: Almeida (2005). Elaboração do autor.

Os principais prejudicados na primeira metade dos anos de 1990 foram os estados, que tiveram perdas de 3,1 p.p. na RD, ao passo que os municípios, ainda que em menor proporção, mantiveram a tendência de ganhos, em 0,3 p.p. Coube aos primeiros arcar com as despesas que proporcionaram os benefícios para a União e os municípios, constituindo-se os mais prejudicados com a Reforma Tributária, promovida pela CF/1988.

A CSLL, de 1989 a 1994, elevou sua participação na receita tributária total de 0,87\% para $3,25 \%$; o IOF de $0,66 \%$ para $2,32 \%$ e a COFINS de $5,36 \%$ para $8,60 \%$ que, em 1990, teve aumentada sua alíquota de $0,5 \%$ para $2,0 \%$. Segundo Varsano et al. (1998, p. 13):

\footnotetext{
A baixa participação da tributação sobre a renda e sobre o patrimônio exprime uma preferência da União por tributos que sejam de mais fácil arrecadação, como os que utilizam o faturamento como base impositiva. Tais tributos, ainda que de pior qualidade, possuem elevada produtividade fiscal, especialmente em contextos inflacionários. Note-se também que suas arrecadações não são partilhadas com as unidades subnacionais, o que é outro motivo para a preferência.
} 
Se a arrecadação da União dos impostos e contribuições sociais federais, divididas com os governos subnacionais, correspondeu a $51,0 \%$ do total em 1988 , esse número caiu para 42,0\% em 1991, sem considerar as contribuições do FGTS, PIS e PASEP (ibidem). Essas contribuições apresentam maior facilidade e seguridade na sua arrecadação do que os impostos, porque são mais difíceis de serem sonegadas.

Os governos subnacionais pressionam o governo federal por mais recursos, entre outros, por meio das emendas ao orçamento federal. A disputa pelos recursos é direcionada pela Comissão Mista de Orçamento e os resultados obtidos pelas unidades constitutivas da federação são bastante variados. Da mesma forma, o governo federal buscou não perder parcela importante de seus recursos, pois além da criação de novas contribuições sociais e o aumento das alíquotas de muitas já existentes, criou-se o Fundo Social de Emergência, em 1994, com duração de dois anos. Esse Fundo permitiu a livre manipulação de $20 \%$ da receita orçamentária de impostos e contribuições sociais, ao desvincular os recursos da União e reter, na esfera do governo federal, parte da receita dos Fundos constitucionais destinados à educação e saúde, retirando substantivas verbas que deveriam ter sido direcionadas principalmente às políticas públicas sociais. Seus objetivos principais estiveram centrados nas tentativas de produzir superávit primário e no pagamento dos juros da dívida pública (interna e externa).

Todos os estados e municípios foram afetados pelo FSE, mas especialmente os mais dependentes das transferências legais, onde estão vinculados os recursos para as políticas públicas, como a educação, principalmente nas regiões mais pobres (Centro-Oeste, Nordeste e Norte) e os pequenos municípios.

As subsequentes edições do $\mathrm{FSE} / \mathrm{FEF}^{11} / \mathrm{DRU}^{12}$ contaram com normas constitucionais para recompensar (parcial e residualmente) as perdas fiscais de estados e municípios.

No país e em países vizinhos latino-americanos cresceu a presença de grandes instituições internacionais no financiamento e, sobretudo, na orientação das questões políticas, institucionais e administrativas relacionadas às políticas públicas a partir dos anos de 1980. A descentralização, para instituições como a Organização das Nações Unidas para a Educação, Ciência e Cultura (UNESCO) e a Organização

\footnotetext{
${ }^{11}$ Fundo de Estabilização Fiscal.

12 Desvinculação das Receitas da União.

Cad. de Pesq. Interdisc. em Ci-s. Hum-s., Florianópolis, v.13, n.103, p.92-114, ago/dez 2012
} 
dos Estados Americanos (OEA), possibilitaria incorporar camadas populacionais excluídas; já para o Banco Mundial, permitiria o desenvolvimento das regras de mercado.

Somado ao aumento das transferências legais relativas à União após a promulgação da CF/1988, o direito social, entendido como seguridade e não como seguro, constituiu-se no fundamento das políticas sociais, aumentando a participação financeira do setor público com a complementação do setor privado.

Ocorreu também a elevação do número de beneficiários na previdência social, dos gastos com o funcionalismo, de ações assistenciais fragmentadas para grupos carentes e da participação social (DRAIBE, 2003).

As despesas públicas passaram a estar sujeitas às determinações de instrumentos constitucionais de iniciativa do Executivo, como consta no art. 165 da CF/1988, entre elas, o Plano Plurianual (PPA), a Lei de Diretrizes Orçamentárias (LDO) e a Lei Orçamentária Anual (LOA).

Dois fatores justificam a ocorrência da despesa orçamentária. Primeiro, a necessidade social que cria demanda para seu atendimento; segundo, deve haver recursos orçamentários ou adicionais propostos pelo Executivo e aprovados pelo Legislativo, desencadeando disputas entre os dois poderes e principalmente entre os parlamentares que compõem a Câmara Alta e a Câmara Baixa.

Os direitos sociais constitucionais foram seriamente prejudicados com as reformas políticas e econômicas neoliberais nos anos de 1990 e 2000. No governo Collor, os gastos com os grupos populacionais mais carentes em áreas como assistência social ${ }^{13}$ e políticas públicas de universalização dos direitos sociais foram reduzidos em 50\% (GOMES, 2006), dentro das medidas necessárias para a reestruturação do capitalismo não só nacional, mas mundial.

As políticas de garantia de renda (como as que compensam o desemprego), previdência e programas assistenciais, bem como as de combate à miséria e de ciência e tecnologia continuaram sob o domínio da União, enquanto que as políticas de prestação de serviços com tendências de universalização passaram para a atribuição dos governos subnacionais, como saúde e educação básica. Aos governos municipais coube a responsabilidade pela oferta dos serviços básicos como a coleta de lixo, infraestrutura urbana, habitação e saneamento, ainda que

\footnotetext{
${ }^{13}$ A assistência social se tornou política pública com a CF/1998, tendo sido ampliada com a Lei $n^{\circ}$ 8.742/1993, também conhecida como Lei Orgânica da Assistência Social (LOAS).
}

Cad. de Pesq. Interdisc. em Ci-s. Hum-s., Florianópolis, v.13, n.103, p.92-114, ago/dez 2012 
fortemente limitados em muitos aspectos pela legislação, supervisão e pelos recursos orçamentários federais, dando margem à abertura dos canais de negociação política e aos acordos clientelísticos quando da transferência negociada de recursos.

As funções de regulação e controle dos programas de políticas públicas foram geralmente exercidas pelo poder público de âmbito estadual, com os princípios, normas, diretrizes e metas determinadas pelo governo federal.

Já a execução de muitos programas sociais foi normalmente delegada aos governos municipais e, também, aos estaduais e às vezes para a iniciativa privada, o que gerou uma multiplicidade de resultados não só pelo alcance sobre os diferentes níveis de governo, mas também pelo grau de descentralização das políticas em jogo.

Ao analisar o modelo da distribuição de competências para as políticas públicas no federalismo brasileiro, que não contou com uma política nacional comandada pelo governo nacional, Arretche (2004, p. 22) afirma que são maiores as chances para o desenvolvimento de "superposição de ações; desigualdades territoriais na provisão de serviços; e mínimos denominadores comuns nas políticas nacionais (...) derivados dos limites à coordenação nacional das políticas", do que para a cooperação federativa.

A correlação entre federalismo fiscal e políticas públicas, que tenha como preocupação a aprovação de mecanismos que determinem relações de dependência eficientes entre os entes federados, minimiza os problemas que levam aos desajustes no financiamento de políticas de maior interesse para o desenvolvimento da nação e ao próprio alcance de seus objetivos, atuando no combate da redução das desigualdades sociais.

\section{Considerações finais}

Se os recursos públicos, muitas vezes, são gastos com pouca ou nenhuma integração das políticas públicas entre os níveis de governo, podendo mesmo caminhar por vias opostas, o efeito isolacionista faz com que o gasto incida sobre os mesmos problemas, de forma cumulativa, minimizando o potencial de criar melhores resultados com recursos que são quase sempre escassos. 
Itamar Franco colocou freio temporário nas rápidas e intensas reformas políticas e econômicas que estavam sendo executadas desde 1990, mas não mexeu nas suas bases. O ministro da Economia nesse período, Fernando Henrique Cardoso, assumiu a tarefa de instalar um novo plano econômico que pudesse conter a alta inflação, tarefa que os planos dos anos anteriores não conseguiram lograr até 1994.

De 1986 a 1994, quatro diferentes moedas e seis planos de estabilização tentaram solucionar os problemas da economia brasileira, mas apenas o último, o Plano Real, obteve maior sucesso, o que levou a mudanças importantes no federalismo brasileiro durante os dois governos de FHC. Mesmo assim, depois da Reforma Tributária promovida pela CF/1988, manteve-se no país uma tributação regressiva, pois as alíquotas na tributação indireta não discriminam sobre a essencialidade dos produtos, o que determina a maior contribuição dos trabalhadores, e não das elites econômicas, no consumo de mercadorias. Ainda, entre outros, destaca-se a incidência dos tributos sobre a renda e os tributos cumulativos da seguridade social, centralizados pela União, dos quais alguns tiveram suas alíquotas aumentadas, ou houve a criação de outros, para evitar perdas substantivas de recursos por parte do governo federal, dificultando o estabelecimento de melhorias qualitativas no STB. 


\section{REFERÊNCIAS}

ARRETCHE, M. T. S. Federalismo e políticas sociais no Brasil: problemas de coordenação e autonomia. São Paulo Perspec., vol. 18, n.2, São Paulo, p. 17-26, abr./jun. 2004. Disponível em: <http://dx.doi.org/10.1590/S0102-

88392004000200003>. Acesso em: 30 mar. 2010.

ABRUCIO, F. L.; COUTO, C. G. O impasse da federação brasileira: o cenário político-financeiro e as suas consequências para o processo de descentralização.

Cadernos CEDEC, n.58, São Paulo, p. 01-41, jul. 1996. Disponível em: $<$ www.cedec.org.br/files pdf/CAD58.pdf>. Acesso em: 29 dez. 2010.

ALMEIDA, M. H. T. Recentralizando a Federação? Rev. Sociol. Polit., n.24, Curitiba, p. 29-40, jun. 2005. Disponível em: <http://dx.doi.org/10.1590/S010444782005000100004> Acesso em: 14 ago. 2011.

AMORIM, E. A. Carga tributária - evolução histórica: uma tendência crescente. BNDES, n.29, Rio de Janeiro, p. 01-08, jul. 2001. Disponível em: $<$ www.bndes.gov.br/SiteBNDES/export/sites/default/.../inf 29.pdf>. Acesso em: 13 dez. 2011.

BRASIL. Constituição da República Federativa do Brasil de 1988. Brasília: Presidência da República, 2008. Disponível em: $<$ http://www.planalto.gov.br/ccivil 03/constituicao/constitui\%C3\%A7ao.htm>. Acesso em: 29 jan. 2008.

CARCANHOLO, M. D. Abertura externa e liberalização financeira: impactos sobre crescimento e distribuição no Brasil dos anos 90. Tese (Pós-Graduação em Economia), Universidade Federal do Rio de Janeiro, Rio de Janeiro, 2002.

CRUZ, R. E. Pacto federativo e financiamento da educação: a função supletiva e redistributiva da União - o FNDE em destaque. Tese (Pós-Graduação em Educação), Universidade de São Paulo, São Paulo, 2009. Disponível em: $<$ http://bdtd.ibict.br >. Acesso em: 30 set. 2010.

DAIN, S. A Economia Política da Reforma Tributária de 2003. Econômica, vol. 7 , n.2, Rio de Janeiro, p. 293-318, dez. 2005. Disponível em:

<www.uff.br/revistaeconomica/v7n2/dain.pdf>. Acesso em: 05 dez. 2011. 
DRAIBE, S. A política social no período $\mathrm{FHC}$ e o sistema de proteção social. Tempo soc., vol. 15, n.2, São Paulo, p. 01-12, nov. 2003. Disponível em:

<http://dx.doi.org/10.1590/S0103-20702003000200004>. Acesso em: 01 jun. 2010.

GOMES, F. G. Conflito social e welfare state: Estado e desenvolvimento social no Brasil. Rev. Adm. Pública, v. 40, n.2, Rio de Janeiro, p. 201-236, mar./abr. 2006. Disponível em: <http://dx.doi.org/10.1590/S0034-76122006000200003>. Acesso em: 05 jun. 2010.

GOMES, G. M; MACDOWELL, M. C. Descentralização política, federalismo e criação de municípios: o que é mau para o econômico nem sempre é bom para o Brasil. Instituto de Pesquisa Econômica Aplicada - IPEA, Texto para Discussão n.706, Brasília, p. 01-27, fev. 2000. Disponível em:

$<$ www.ipea.gov.br/pub/td/td 2000/td 706.pdf >. Acesso em: 30 abr. 2010.

PINTO, J. M. R. Os recursos para a educação no Brasil no contexto das finanças públicas. Brasília: Plano, 2000.

REZENDE, F. Federalismo fiscal no Brasil. Rev. Econ. Polit., vol. 15, n.3, São Paulo, p. 05-17, abr./jun. 1995. Disponível em: <www.rep.org.br/pdf/59-1.pdf> Acesso em: 10 ago. 2011.

SOUZA, C. Federalismo e gasto social no Brasil: tensões e tendências. Lua Nova, n.52, São Paulo, p. 05-28, 2001. Disponível em: <http://dx.doi.org/10.1590/S010264452001000100002>. Acesso em: 02 ago. 2011.

SRF, Secretaria da Receita Federal. Carga Fiscal no Brasil. Brasília: s/e, 1996. Disponível em: < http://www.receita.fazenda.gov.br>. Acesso em 15 ago. 2011.

TORRES, D. et al. Revelando o Sistema Tributário Brasileiro. São Paulo: SINAFRESP, 2003.

VARSANO, R. A evolução do sistema tributário brasileiro ao longo do século: anotações e reflexões para futuras reformas. Instituto de Pesquisa Econômica Aplicada - IPEA, Texto para discussão n. 405, Rio de Janeiro, p. 01-37, jan. 1996. Disponível em: <www.ipea.gov.br/pub/td/td0405.pdf>. Acesso em: 05 ago. 2011.

VARSANO, R. et al. Uma análise da carga tributária no Brasil. Instituto de Pesquisa Econômica Aplicada - IPEA, Texto para discussão n. 583, Rio de Janeiro, p. 01-71, ago. 1998. Disponível em: $<$ portal2.unisul.br/content/...dos.../livro Tributos no Brasil.pdf> >. Acesso em: 05 ago. 2011. 
Artigo:

Recebido em: 21/07/2012 Aceito em: 20/12/2012 